\title{
Dilution of the Antarctic ozone hole into southern midlatitudes, 1998-2000
}

\author{
J. Ajtić, ${ }^{1,2}$ B. J. Connor, ${ }^{2}$ B. N. Lawrence, ${ }^{3}$ G. E. Bodeker, ${ }^{2}$ K. W. Hoppel, ${ }^{4}$ \\ J. E. Rosenfield, ${ }^{5}$ and D. N. Heuff ${ }^{1}$ \\ Received 30 December 2003; revised 3 June 2004; accepted 18 June 2004; published 14 September 2004.
}

[1] The reduction in southern midlatitude ozone is quantified by evaluating the trajectories of ozone-depleted air masses, assuming that photochemical recovery of ozone in advected air parcels can be ignored. This procedure is carried out for the 3 months from 15 October to 15 January for each of the years 1998, 1999, and 2000. Two distinct source regions, the vortex core and the vortex edge, are considered, and for each day, diabatic reverse domain filling calculations are performed for an ensemble of parcels between $30^{\circ} \mathrm{S}$ and $60^{\circ} \mathrm{S}$ and $400-700 \mathrm{~K}$ in altitude. In 1998, 1999, and 2000 the mean calculated ozone reduction is 16,18 , and 19 DU, respectively. Air parcels from the vortex edge region are significant contributors to the reduction, especially during spring. Results for four longitudinal and three latitudinal midlatitude subregions are also presented. A comparison with the Total Ozone Mapping Spectrometer measurements of total column ozone shows that without the dilution, ozone over Southern Hemisphere midlatitudes would be $5-6 \%$ higher during spring and summer. This result is probably an overestimate due to the neglect of photochemical recovery. INDEX TERMS: 0341 Atmospheric Composition and Structure: Middle atmosphere - constituent transport and chemistry (3334); 3334 Meteorology and Atmospheric Dynamics: Middle atmosphere dynamics (0341, 0342); 3399 Meteorology and Atmospheric Dynamics: General or miscellaneous

Citation: Ajtić, J., B. J. Connor, B. N. Lawrence, G. E. Bodeker, K. W. Hoppel, J. E. Rosenfield, and D. N. Heuff (2004), Dilution of the Antarctic ozone hole into southern midlatitudes, 1998-2000, J. Geophys. Res., 109, D17107, doi:10.1029/2003JD004500.

\section{Introduction}

[2] Averaged over the period 1997-2001, total column ozone over southern midlatitudes was $6 \%$ below pre-1980 average levels, with the maximum decrease in springtime and summertime [World Meteorological Organization $(W M O), 2003]$. A number of studies have shown that in situ chemical destruction of ozone, either through heterogeneous reactions on sulfate aerosols [e.g., Hofmann and Solomon, 1989; Bregman et al., 1997; Knight et al., 1998] or initiated by the transport of ozone-depleting chemicals from the polar vortex [e.g., Prather and Jaffe, 1990; Norton and Chipperfield, 1995; Chipperfield, 1999] contribute to the observed ozone reduction. If transport of polar air to midlatitudes occurs after the onset of polar

\footnotetext{
${ }^{1}$ Department of Physics and Astronomy, University of Canterbury, Christchurch, New Zealand.

${ }^{2}$ National Institute of Water and Atmospheric Research, Omakau, Central Otago, New Zealand.

${ }^{3}$ British Atmospheric Data Centre, Rutherford Appleton Laboratory, Didcot, UK

${ }^{4}$ Remote Sensing Physics Branch, Naval Research Lab, Washington, DC, USA.

${ }^{5}$ Goddard Earth Sciences and Technology Center, NASA/Goddard Space Flight Center, Greenbelt, Maryland, USA.
}

Copyright 2004 by the American Geophysical Union. 0148-0227/04/2003JD004500 ozone depletion, then midlatitude ozone is reduced not only through ensuing chemical depletion caused by remaining active substances, but also through two other mechanisms. First, the presence of isolated ozone-depleted air masses causes a transient ozone reduction over the geographical region where they are located [e.g., Atkinson and Plumb, 1997; Kirchhoff et al., 1997; Pérez et al., 2000; Brinksma et al., 2002; Ajtić et al., 2003]. A longer lasting, and not as conspicuous effect occurs when these isolated air masses depleted in ozone are diluted into midlatitude air. Modelling studies by Prather et al. [1990], Mahlman et al. [1994], Eckman et al. [1996], and Chipperfield [1999] showed a decrease of $2-5 \%$ in southern midlatitude total ozone as a consequence of dilution. Li et al. [2002] indicated that $\sim 10 \%$ of the September-October southern midlatitude ozone trend is caused by the presence of the Antarctic vortex air. Chipperfield [2003] demonstrated that about 30\% of the southern midlatitude ozone trend in springtime and summertime is a result of dilution. Although the process of dilution has previously been studied, it remains "poorly quantified at present" [WMO, 2003].

[3] In this paper, dilution of the Antarctic ozone hole into southern midlatitudes $\left(30^{\circ}-60^{\circ} \mathrm{S}\right)$ is quantified for spring and summer of the years 1998, 1999 and 2000. The data and method used are described in section 2. The results are presented in section 3 , and considered in the context of total column ozone in section 4. A discussion of the results is 
given in section 5, and the conclusions are presented in section 6 .

\section{Data and Method}

[4] Diabatic reverse domain filling (RDF) calculations [Sutton et al., 1994] were performed for parcels initialized on a $1^{\circ}$ longitude by $1^{\circ}$ latitude grid, spanning the region $30^{\circ} \mathrm{S}$ to $60^{\circ} \mathrm{S}$. The parcels were initialized on seven isentropic surfaces, from $400 \mathrm{~K}$ to $700 \mathrm{~K}, 50 \mathrm{~K}$ apart. The period examined in each of the years 1998, 1999, and 2000 was 15 October to 15 January of the following year. The day to which RDF calculations were run was 10 October (hereafter referred to as the initial day).

\subsection{Trajectory Code and Meteorological Data}

[5] The trajectory code used a spherical coordinate system, except for regions within $25^{\circ}$ of the poles, where polar-stereographic coordinates were used. The vertical coordinate was potential temperature. A fourth-order Runge-Kutta method was used to integrate the advection equations, and bilinear interpolation was used to calculate winds at parcel positions. A 2 hour time step was used. Schoeberl and Sparling [1995] showed that with this integration scheme and time step, the computational errors are negligible.

[6] Daily temperature, wind and geopotential height fields from the United Kingdom Meteorological Office (Met Office) analyses [Swinbank and O'Neill, 1994] were used. For vertical motion, daily fields of potential temperature change (hereafter referred to as heating rates) were used. Heating rates were derived from daily fields of temperature change, which in turn were calculated using a radiative transfer model and Met Office temperature observations [Rosenfield et al., 1994; Rosenfield and Schoeberl, 2001].

[7] The longest time period covered by our trajectory calculations was 97 days. The uncertainties in individual trajectories over a long period of time can be substantial [Morris et al., 1995; Stohl, 1998]. However, trajectory calculations performed for ensembles of parcels have smaller uncertainties [Morris et al., 1995], and have been employed in a number of studies to cover relatively long periods of time [e.g., Manney et al., 1994; Rosenfield and Schoeberl, 2001; Öllers et al., 2002]. With this caveat, the conclusions drawn in this work were based on the trajectories of a large number of parcels.

\subsection{Ozone Depletion in the Antarctic Vortex}

[8] The vertical profiles of ozone depletion inside the Antarctic vortex were taken from Hoppel et al. [2003]. Ozone depletion calculations were based on a vortex averaged descent method [Hoppel et al., 2002] and used ozone measurements from the Polar Ozone and Aerosol Measurement III instrument [Lucke et al., 1999] and heating rates calculated as in Rosenfield et al. [1994]. Ozone depletion calculations were performed from 1 July to 10 October. Most of the ozone depletion inside the Antarctic

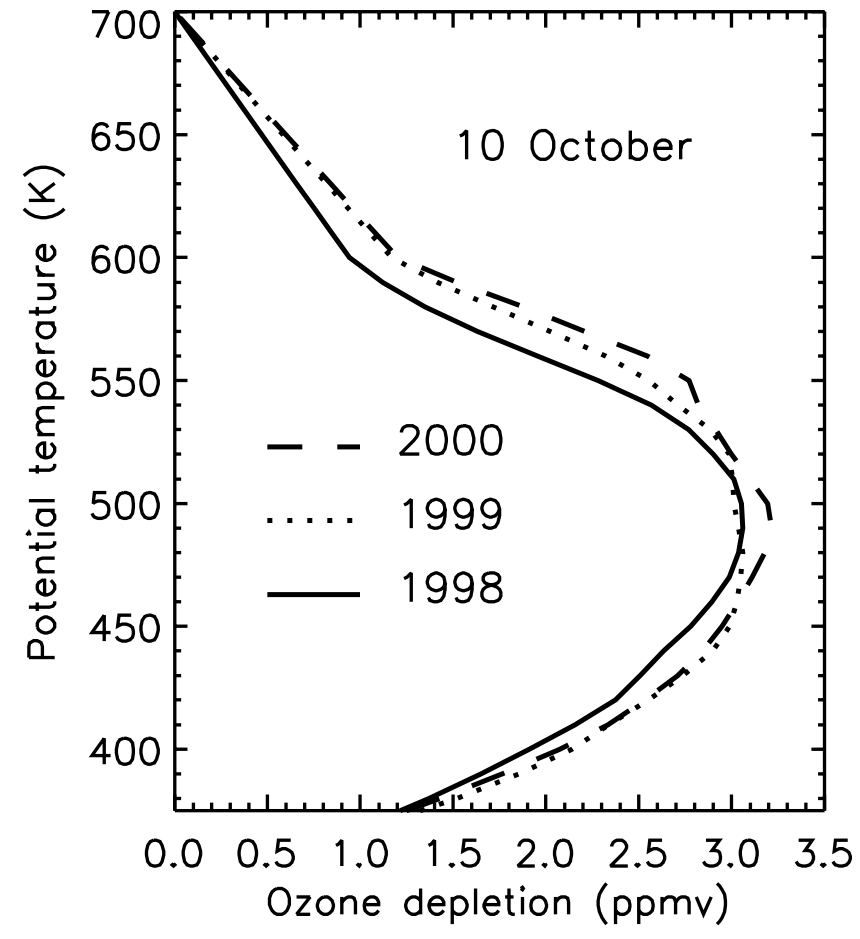

Figure 1. Volume mixing ratio of depleted ozone (in ppmv) as a function of potential temperature (in K) in the Antarctic vortex, for the years 1998 (solid line), 1999 (dotted line), and 2000 (dashed line).

vortex was captured over this period as the ozone destruction processes usually cease in late September or early October [Godin et al., 2001]. As the calculated ozone depletion of Hoppel et al. [2003] above $600 \mathrm{~K}$ reflects normal ozone photochemistry, small modifications to the original depletion curves above $600 \mathrm{~K}$ were made by linearly interpolating the mixing ratio of depleted ozone $\left(\mathrm{u}_{\mathrm{dO}_{3}}\right)$ from the calculated value at $600 \mathrm{~K}$ to zero at $700 \mathrm{~K}$ (Figure 1).

[9] Two distinct regions within the Antarctic vortex were considered: the vortex core, where mixing is relatively strong, and the vortex edge region (region between the vortex core and the exterior of the vortex) of weak mixing [Lee et al., 2001; Öllers et al., 2002]. These two regions were defined according to Nash et al. [1996], i.e., the vortex core as the region within the poleward vortex boundary, and the vortex edge region as the region between the poleward and equatorward vortex boundary. On the basis of Lee et al. [2001] ozone depletion inside the core was taken to be spatially uniform. In the edge region, where temperatures are generally higher [Tao and Tuck, 1994] and ozone depletion is not as severe as in the core [Lee et al., 2001], it was assumed that $\mathrm{u}_{\mathrm{dO}_{3}}$ is a linear function of potential vorticity $(\mathrm{PV})$, decreasing from the value prescribed for the core at the poleward vortex boundary, to zero at the equatorward vortex boundary (for further details, see Ajtic [2003]). Hoppel et al. [2003] performed calculations for the vortex region poleward of the vortex edge [Nash et al., 1996], thus encompassing the vortex core and a part of the vortex edge region as defined here. Therefore in this work, ozone depletion inside the core was derived such that the 
total number of depleted ozone molecules poleward of the vortex edge is equal to the results of Hoppel et al. [2003].

\subsection{Ozone Depletion Calculations I}

[10] The midlatitude reduction in ozone caused by the presence of air that underwent chemical ozone depletion in the Antarctic vortex (hereafter referred to as ozone depletion for simplicity) was calculated under two assumptions. First, it was assumed that the mixing ratio of depleted ozone is conserved along the parcel trajectories, i.e., that the photochemical lifetime of ozone is long [Brasseur and Solomon, 1986], and that ozone destroyed inside the vortex does not recover over a period of a few months. Therefore advecting the mixing ratio of depleted ozone is equivalent to advecting the observed and undepleted ozone and calculating the difference [Knudsen et al., 1998; Knudsen and Groo $\beta$, 2000]. Second, it was assumed that by averaging the results over a large geographical region, the errors arising from the omission of explicit representation of mixing in RDF calculations can be neglected (further discussed in section 5).

[11] For each analysis day, $1^{\circ} \times 1^{\circ}$ fields of $\mathrm{u}_{\mathrm{dO}_{3}}$ on the seven isentropes were derived by running RDF calculations back to 10 October. On this day, parcels located inside the Antarctic vortex were identified by their PV value and labelled with a corresponding $\mathrm{u}_{\mathrm{dO}_{3}}$ (section 2.2). For each analysis day, ozone depletion in a geographical region was then calculated as a column of depleted ozone between the vertical limits of the model domain. The number of depleted ozone molecules, $N_{\theta}$, in a layer centered around the potential temperature surface $\theta$, was derived as:

$$
N_{\theta}=\frac{1}{k_{B}} \sum_{i^{\prime}=1}^{2} \sum_{i=1}^{n\left(i^{\prime}\right)} \mathrm{u}_{\mathrm{dO}_{3} \theta_{\text {init }}, i} \frac{p_{\theta, i}}{T_{\theta, i}} V_{\theta, i}
$$

where $i^{\prime}=1$ denotes core parcels and $i^{\prime}=2$ denotes edge region parcels, and parcels within those two classes are counted by $i$. The mixing ratio of depleted ozone (a function of the parcel's isentrope on the initial day, $\left.\theta_{\text {init }}\right)$, pressure, temperature and volume corresponding to vortex parcels are $\mathrm{u}_{\mathrm{dO} 3 \theta \text { init,i }}, p_{\theta, i}, \quad T_{\theta, i}$ and $V_{\theta, i}$, respectively, and $k_{B}$ is Boltzmann's constant. The base area of the spatial box surrounding each vortex parcel was $1^{\circ}$ longitude by $1^{\circ}$ latitude. The isentropes around which the summation was performed, as well as the vertical limits of the model domain, are discussed in the next section.

[12] The contribution of a parcel to the total depletion is directly influenced by the pressure and volume associated with that parcel (equation (1)). For example, if a vortex parcel is moving northward or downward, the contribution of this parcel increases (for a detailed discussion, see Ajtić [2003]). Hence motion of parcels in the domain can represent a source of spurious variations in the calculated number of depleted ozone molecules. Additional constraints introduced to force mass conservation are discussed in section 2.5.

\subsection{Model Domain}

[13] The vertical region examined in this study was between the isentropes of $375 \mathrm{~K}$ and $725 \mathrm{~K}$. It is in this region of the stratosphere that ozone is most abundant and where ozone depletion inside the vortex occurs. Examination of heating rates (section 2.1) over the October-January period showed that, on average, vortex air from this vertical region did not ascend to higher isentropes by the time it reached southern midlatitudes. Therefore there was no need to extend the top limit of the domain. The bottom limit of the model domain is higher than the tropopause [Holton et al., 1995; Tuck and Proffitt, 1997], allowing exclusion of the troposphere from the calculations. The estimated impact of dilution on the tropospheric column ozone is discussed in section 5. With the chosen vertical limits of the domain, any air parcels descending below $375 \mathrm{~K}$ or ascending above $725 \mathrm{~K}$, at any point in their trajectories, were not included in the ozone depletion calculations.

[14] Changes in the thickness and density of the air column between $375 \mathrm{~K}$ and $725 \mathrm{~K}$ directly influence the number of depleted ozone molecules in the domain. Examination of the 375-725 K layer in the Southern Hemisphere (SH) over the October-January period showed an increase in both thickness and density. As a consequence, the total number of calculated depleted ozone molecules was expected to increase over the analysis period (equation (1)). In other words, day-to-day variations in the domain's physical properties would give rise to spurious variations in the total number of depleted ozone molecules. This effect is different from the effect arising when depleted ozone molecules move inside the domain (section 2.3). A scaling method, introduced in section 2.5, was used to correct the results for the unrealistic change in the number of depleted ozone molecules.

[15] The number of isentropes used in this study was determined after performing tests in which differences between various choices were analyzed. The tests showed that an increased number of isentropes did not increase the precision of the results, and seven isentropes, 400-700 K, with $\Delta \theta=50 \mathrm{~K}$, were chosen for the calculations (for further details, see Ajtić [2003]). Furthermore, in these tests, the ozone depletion uncertainties arising from the errors in the Met Office temperature fields (taken as $1 \mathrm{~K}$ throughout the vertical domain [Swinbank and O'Neill, 1994; Manney et al., 2003]) were estimated to be at most 5\%.

\subsection{Ozone Depletion Calculations II}

[16] The key assumption in the depletion calculations (equation (1)) was that the mixing ratio of depleted ozone can be advected unchanged along the trajectories. However, the physical property which one might expect to be conserved is the number of depleted ozone molecules. The ozone depletion calculations therefore need to include a method to remove any possible inconsistencies between the advection and the mass field. In this section, the method incorporated into the calculations to achieve the above aim is described.

\subsubsection{Validation of RDF Calculations}

[17] The first step in the method was to examine the spatial representation of sources of air on the initial day. Given that the parcels were advected backward for a considerable time to their initial positions, it is possible that those positions could be an unrepresentative spatial sample of the initial day. To assess this, RDF calculations were performed for globally distributed parcels on a $1^{\circ} \times 1^{\circ}$ grid, on the seven isentropes. The parcels were advected back- 
ward in time to 10 October. On each analysis day, the potential temperature, longitude and latitude of the parcels' initial positions were examined to check whether there were any regions that were not well sampled. This test showed that RDF calculations did provide a realistic sample of the origin of the air masses (for further details, see Ajtic [2003]). Furthermore, the latitude distribution of the initial positions showed that the number of parcels coming from the polar region decreased with time. For example, in 1998, at the end of the 3 months, only $\sim 17 \%$ of the initialized parcels originated in the polar region, compared to $\sim 31 \%$ at the beginning of the period. Heating rates (section 2.1) in the polar region showed that this was caused by the transport of air below the lower limit of the model domain (as expected according to Prather et al. [1990], Li et al. [2002], and Öllers et al. [2002]). To formulate the problem of conservation of the number of depleted ozone molecules, this effect must be accounted for.

\subsubsection{Mass Conservation: Refinement I}

[18] The above conclusion indicates that throughout the examined period, vortex air was leaving the vertical domain, causing the total number of depleted ozone molecules within the domain to decrease. In this step, a method for inferring the number of depleted ozone molecules present in the domain is introduced.

[19] The number of depleted ozone molecules in the model domain, on any given day, was calculated assuming the following: (1) all of the vortex air between $375 \mathrm{~K}$ and $725 \mathrm{~K}$ is present in the domain on the first day of calculations, i.e., 15 October; (2) the number of parcels originating in the vortex is directly proportional to the fraction of the vortex present in the domain on the given day, i.e., if the number of parcels originating in the vortex is $n_{0}$ on 15 October, and $n_{n}$ on some other day, then the fraction of the initial vortex present in the domain is $n_{n} / n_{0}$; (3) assuming that the depleted ozone molecules are uniformly spread throughout the vortex leads to $n_{n} / n_{0}$ being directly proportional to the number of depleted ozone molecules inside the domain, i.e., if $N_{0}$ is the total number of depleted ozone molecules inside the vortex on 10 October, then on the $n$th day, the number of depleted ozone molecules in the domain, $N_{n}$, is $N_{n}=N_{0} \cdot n_{n} / n_{0}$.

[20] The initialized parcels were the same as in section 2.5.1. The calculations for core and edge region parcels were performed separately. As expected, the results for $n_{n} / n_{0}$ showed that the number of globally distributed vortex parcels inside the domain decreased with time. For example, in 1998 , at the end of the period only $\sim 48 \%$ and $\sim 63 \%$ of core parcels and edge region parcels, respectively, were still present in the domain.

[21] Under the third assumption, the $n_{n} / n_{0}$ ratios also represent the fraction of the initial number of depleted ozone molecules still inside the examined domain. However, this assumption is only a very coarse estimate. The number concentration of depleted ozone in the vortex varies with height (Figure 1), and the number of depleted ozone molecules that leave the model domain depends on the original height of the parcels. RDF calculations performed here only contain information about vortex parcels present in the domain, and, consequently, about the number of depleted ozone molecules associated with those parcels. The exact information about vortex parcels that leave the domain, and the associated depleted ozone molecules, could be obtained by initializing air parcels inside the vortex, and advecting them forward in time. To test the validity of the third assumption without performing forward trajectory calculations, the $n_{n} / n_{0}$ ratios in a somewhat different interpretation were compared with some of the results presented in recent publications.

[22] If the $n_{n} / n_{0}$ ratios are taken as the mass ratios, i.e., to represent a fraction of the initial vortex mass inside the domain, then the assumption of the uniform distribution of depleted ozone molecules inside the vortex is not included. However, mass nonuniformity in the vortex is still neglected. In this interpretation, the complement ratios, $\left(1-n_{n} / n_{0}\right)$, represent "vortex mass leakage" from the domain. For example, in 1998, between 15 October and 31 October, the average rate at which the vortex core material left the domain was $0.71 \%$ of the vortex core mass per day. The result of the Öllers et al. [2002] study, in which downward transport of Antarctic vortex air (from the region comparable to our vortex core) was examined, showed that for October 1998, mass exchange rate was $4.13 \%$ per week, i.e., $0.59 \%$ per day. If both the vortex core and the vortex edge region are considered in our analysis, then the average flow rate was $0.91 \%$ of the vortex mass per day. This result is slightly less than the result of Li et al. [2002], showing the flow rate of $0.98 \%$ of the vortex mass per day (from the region comparable to our vortex core and edge region).

[23] There are a number of differences between the studies that can explain the disagreement. The vertical boundaries of the domains do not match and the meteorological data used in the studies are not identical. Furthermore, Li et al. [2002] analyzed different years, i.e., 19931997 (and noted an interannual variability in the transport) and presented the averaged results for the SeptemberOctober period, which are higher than the results for the month of October. Nevertheless, the broad agreement of our result with these two studies gives confidence to the conclusions that were drawn from inference of the vortex leakage through the lower boundary of the domain.

\subsubsection{Mass Conservation: Refinement II}

[24] On the basis of the results of section 2.5.2, the mass conservation problem can be formulated as follows: In the $375-725 \mathrm{~K}$ layer over the whole globe, the number of depleted ozone molecules originating in the vortex (calculated using equation (1)) must equal the total number of depleted ozone molecules contained in the fraction of the vortex present in this vertical layer. This restriction effectively removes the unrealistic change in the number of depleted ozone molecules that is otherwise present in the calculations (sections 2.3 and 2.4).

[25] The restriction was incorporated into the analysis as follows. First, the total number of depleted ozone molecules in the vortex between $375 \mathrm{~K}$ and $725 \mathrm{~K}$, on 10 October, was calculated. This number was then scaled with the $n_{n} / n_{0}$ ratios (section 2.5.2) to yield a number of depleted ozone molecules in the model domain on each examined day, $N_{n}$. Next, the total number of depleted ozone molecules, originating in the vortex, spread all over the globe in the $375-$ $725 \mathrm{~K}$ layer, $N_{\text {calc }}$, was calculated using equation (1). The calculations for the vortex core and the vortex edge region were performed separately. Finally, the $N_{\text {calc }} / N_{n}$ ratios were used to apply mass flux constraints to the analysis. Since 


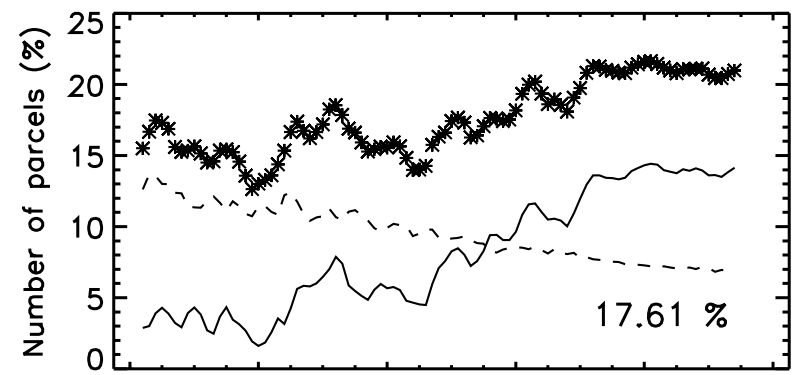

$13 / 10 \quad 02 / 11 \quad 22 / 11 \quad 12 / 12 \quad 01 / 01 \quad 21 / 01$

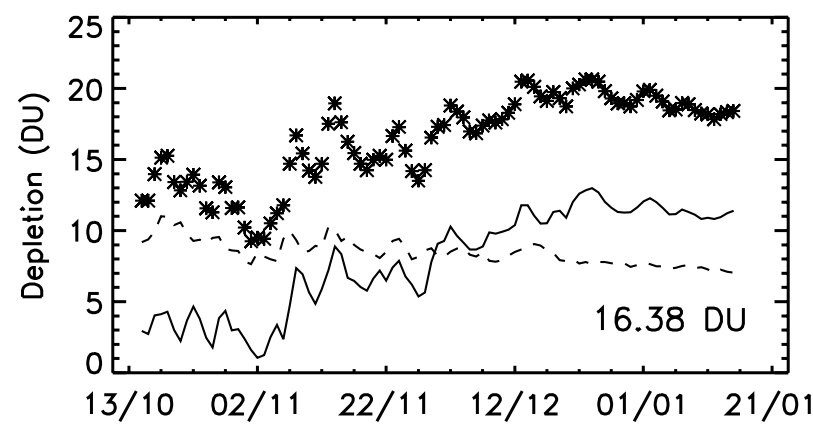

Figure 2. Number of vortex parcels as a percent of the total number of (left) initialized parcels and (right) depletion in southern midlatitudes in the 375-725 K layer in 1998 (solid line is vortex core; dashed line is edge region; asterisked line is vortex core and edge region). The mean values over the examined period are indicated on the lower right.

these ratios were derived for the number of depleted ozone molecules spread around the whole globe, mass conservation was enforced globally. As a result, by using the same ratios to scale the midlatitude results, global mass conservation constricted depletion in midlatitudes.

\section{Dilution Effect: Southern Midlatitudes and Subregions in 1998-2000}

[26] The ozone depletion calculations were performed for 1998, 1999 and 2000, for southern midlatitudes as well as for four longitudinal subregions: "Africa" with longitudes $0^{\circ}-90^{\circ} \mathrm{E}$, "Australia and New Zealand" with longitudes $90^{\circ}-180^{\circ} \mathrm{E}$, "Pacific" with longitudes $180^{\circ}-270^{\circ} \mathrm{E}$, and "South America" with longitudes $270^{\circ}-360^{\circ} \mathrm{E}$, and three latitudinal subregions: $60^{\circ}-50^{\circ} \mathrm{S}, 50^{\circ}-40^{\circ} \mathrm{S}$ and $40^{\circ}-30^{\circ} \mathrm{S}$.

[27] As an example, the time evolution of the number of vortex parcels and ozone depletion in southern midlatitudes between 15 October 1998 and 15 January 1999, is shown in Figure 2 (the results for 1999 and 2000 exhibit similar features). At the beginning of the period, both core and vortex edge parcels were present in midlatitudes. This results from parts of the vortex being situated north of $60^{\circ} \mathrm{S}$. Over the analyzed period, the total number of vortex parcels present in midlatitudes increased, with more parcels from the core and fewer parcels from the edge region reaching midlatitudes. Similarly, depletion caused by the presence of vortex edge region parcels reached a maximum early in the period, while depletion caused by vortex core parcels peaked in late December.

[28] The mean (averaged over the 15 October-15 January period) ozone depletion in southern midlatitudes and subregions for 1998-2000 is given in Table 1. The mean depletion was largest in 2000 , caused mainly by two factors. First, ozone depletion in the vortex was most severe in 2000 (Figure 1). Second, a relatively high number of vortex core parcels was present in midlatitudes on the $400 \mathrm{~K}$ isentrope, where air is most dense and the contribution to the total depletion is highest.

[29] The time-averaged influence of the Antarctic ozone hole (in terms of the number of parcels and ensuing ozone depletion) in all of the examined years was most pronounced in the South America and Africa regions. The primary cause for this was the positioning of the vortex prior to breakdown; that is, there were many instances of the vortex protruding into those two longitudinal subregions, resulting in a marked, but transient, reduction in ozone. After vortex breakdown this longitudinal contrast quickly dissipated (see below). It is also evident from Table 1 that the impact of the Antarctic ozone hole decreased with increasing latitude. This was again caused mainly by the more frequent presence of the vortex in the regions of higher latitudes.

[30] Two sets of additional RDF calculations for 1998 were performed to estimate uncertainties of the results presented in Table 1. In the first test, RDF trajectories were run back to different initial days, 3 October and 17 October, to examine the sensitivity of the results to the initial conditions, e.g., the size of the vortex and the filamentation occurring prior to the initial day. The size of the vortex on the initial day directly influenced the number of vortex parcels recognized in the calculations. Furthermore, the recognition of vortex parcels was limited by the lowresolution PV field on the initial day, in which many finescale features were not distinguished. This affected vortex edge region parcels more than core parcels, as the filaments peeling off the vortex usually originate in the edge region [e.g., Bowman, 1993]. In our case, the differences between the runs with 3 October and 10 October as the initial days were larger than with 10 October and 17 October as the initial days. The main reason behind this was a filament peeling off from the vortex between 3 October and 10 October [see Öllers et al., 2002, Figure 6]). In the second test of additional calculations, zonal and meridional wind fields perturbed with normally distributed random

Table 1. Depletion in Midlatitudes and Subregions in 1998, 1999, and $2000^{\mathrm{a}}$

\begin{tabular}{lccc}
\hline & \multicolumn{3}{c}{ Depletion } \\
\cline { 2 - 4 } \multicolumn{1}{c}{ Region } & 1998 & 1999 & 2000 \\
\hline Southern Hemisphere midlatitudes & 16 & 18 & 19 \\
Africa & 18 & 23 & 20 \\
Australia + New Zealand & 14 & 14 & 15 \\
Pacific & 15 & 14 & 16 \\
South America & 18 & 23 & 25 \\
$60^{\circ}-50^{\circ} \mathrm{S}$ & 36 & 40 & 36 \\
$50^{\circ}-40^{\circ} \mathrm{S}$ & 12 & 14 & 17 \\
$40^{\circ}-30^{\circ} \mathrm{S}$ & 6 & 7 & 9 \\
\hline
\end{tabular}

${ }^{\text {a}}$ Depletion is in DU. 
Table 2. Depletion in Midlatitudes and Subregions for 15 October-14 November, 15 November-14 December, and 15 December-15 January ${ }^{\mathrm{a}}$

\begin{tabular}{lccc}
\hline \multicolumn{1}{c}{ Region } & \multicolumn{1}{c}{ Depletion } \\
\cline { 2 - 4 } & 15 Oct. -14 Nov. & 15 Nov. -14 Dec. & 15 Dec. -15 Jan. \\
\hline Southern Hemisphere midlatitudes & 15 & 19 & 20 \\
Africa & 20 & 22 & 20 \\
Australia + New Zealand & 8 & 14 & 20 \\
Pacific & 10 & 17 & 19 \\
South America & 23 & 23 & 32 \\
$60^{\circ}-50^{\circ} \mathrm{S}$ & 42 & 39 & 19 \\
$50^{\circ}-40^{\circ} \mathrm{S}$ & 8 & 16 & 11 \\
$40^{\circ}-30^{\circ} \mathrm{S}$ & 2 & 8 & \\
\hline
\end{tabular}

${ }^{\mathrm{a}}$ Depletion is in DU.

errors, with a mean of $0 \mathrm{~m} / \mathrm{s}$ and standard deviation of $6 \mathrm{~m} / \mathrm{s}$ (from UK Met Office Correlative Analyses: Data Quality, on the British Atmospheric Data Centre web page www.badc.rl. ac.uk), were used. The perturbations were introduced over the 10 October 1998-15 January 1999 period. Overall, the tests showed that the results are more sensitive to the initial conditions than to the perturbations in winds.

[31] The combined relative uncertainties in the depletion results, including the uncertainties arising from the errors in the temperatures used (section 2.4), ranged from $25 \%$ to $60 \%$, depending on the region. The uncertainties were largest in the $40^{\circ}-30^{\circ} \mathrm{S}$ region, and smallest in the $60^{\circ}-$ $50^{\circ} \mathrm{S}$ region. In $\mathrm{SH}$ midlatitudes and longitudinal subregions, the uncertainties were $33-43 \%$. The interannual variability of the results for each region was within the estimated uncertainties. This was also true for the longitudinal differences in depletion.

[32] To examine how depletion changed from month to month, the depletion results (averaged over years 19982000 ) in three periods, 15 October to 14 November, 15 November to 14 December, and 15 December to 15 January, are given in Table 2. The results show that depletion in midlatitudes increased from month to month. The increase was especially marked in the Australia and New Zealand and the Pacific regions, where in October and November the influence of the Antarctic ozone hole was not as pronounced as in the other two longitudinal subregions. During the December-January period, when the total amount of ozone plays a crucial role in the ultraviolet (UV) exposure at the Earth's surface, ozone depletion was the same in all of the longitudinal subregions. The reason for this is that in summer, the Antarctic vortex remnants are well mixed with midlatitude air. In the latitudinal subregions, with the exception of the $60^{\circ}-50^{\circ} \mathrm{S}$ region, northward transport of vortex air following vortex breakdown [e.g., Ajtić et al., 2003] caused depletion to increase from month to month.

[33] Further, the significance of depletion from the edge region was examined by calculating its contribution to the total depletion. Three periods were analyzed: the whole period, 15 October-15 January, the period prior to vortex breakdown, 15 October-31 October, and the period after vortex breakdown, 1 January-15 January. The results show that on average, more than $40 \%$ of the total depletion in midlatitudes was caused by the presence of vortex edge region parcels. The contribution of the edge region depletion varied within the subregions. For example, in the Australia and New Zealand and the Pacific regions, as well as north of $50^{\circ} \mathrm{S}$, the contribution represented more than a half of the total depletion. During October, when the Antarctic vortex core is well isolated from midlatitude air [e.g., Bowman, 1993; Pierce and Fairlie, 1993; Waugh et al., 1997], more than $60 \%$ of the total depletion was caused by parcels originating in the vortex edge region. However, in January, after the vortex breakdown and the ensuing rapid mixing of the vortex air with midlatitude air [Waugh and Rong, 2002], depletion caused by the presence of core parcels became a dominant part of the total depletion.

\section{Relative Changes in Ozone}

[34] Daily values of the Total Ozone Mapping Spectrometer (TOMS) ozone data [McPeters et al., 1998] in southern midlatitudes and subregions were compared with the calculated daily values of ozone depletion. The days when TOMS was not operational or the data were incomplete, were excluded from the analysis. The mean values (over the examined period and over all 3 years) of ozone depletion expressed as a percent of the measured total ozone, are given in Table 3 . On average, in midlatitudes there would have been $5-6 \%$ more ozone without the influence of the Antarctic ozone hole. In the longitudinal subregions, the time-averaged impact was least pronounced in the Australia and New Zealand region and most pronounced in the South America region. The longitudinal differences diminished during the 15 December-15 January period (Table 3 ), when depletion presented $6-7 \%$ of the measured total column ozone in all of the longitudinal subregions.

[35] In midlatitudes, depletion as a percent of the total column ozone generally increased with time, reaching

Table 3. Depletion in Midlatitudes and Subregions as a Percent of Total Column Ozone Measured by TOMS for 15 October15 January and 15 December-15 January

\begin{tabular}{lcc}
\hline & \multicolumn{2}{c}{ Depletion, \% } \\
\cline { 2 - 3 } \multicolumn{1}{c}{ Region } & 15 Oct. -15 Jan. & 15 Dec. -15 Jan. \\
\hline Southern Hemisphere midlatitudes & 5.6 & 6.6 \\
Africa & 6.5 & 6.5 \\
Australia + New Zealand & 4.3 & 6.9 \\
Pacific & 4.6 & 6.2 \\
South America & 7.2 & 6.7 \\
$60^{\circ}-50^{\circ} \mathrm{S}$ & 11.2 & 9.9 \\
$50^{\circ}-40^{\circ} \mathrm{S}$ & 4.4 & 6.4 \\
$40^{\circ}-30^{\circ} \mathrm{S}$ & 2.3 & 4.2 \\
\hline
\end{tabular}


values higher than the average in December and January. This overall behavior is in agreement with the model studies of Prather et al. [1990], Mahlman et al. [1994], Eckman et al. [1996], and Chipperfield [1999]. Even though a direct comparison of our results with theirs is not possible, it should be noted that all of them showed a reduction of approximately $2-5 \%$ in total column ozone, either in southern midlatitudes or in a midlatitude subregion, as a consequence of dilution. The results in Table 3 indicate that according to our method, the impact of dilution is somewhat higher. The differences are especially evident in December 1999 and January 2000, when depletion was $7-8 \%$ of the total column ozone in midlatitudes. A likely reason that could account for some of the differences between our result and the results of the above studies, is the exclusion of ozone recovery in our analysis.

[36] The depletion results, expressed as a percent of undepleted ozone (the sum of the observed total ozone and ozone depletion), can be used to estimate an increase in erythemal UV radiation. Each $1 \%$ decrease in ozone corresponds to $1.2 \%$ increase in erythemal UV [McKenzie et al., 1999, and references therein]. Our results therefore indicate that, on average in midlatitudes, an increase of 6$7 \%$ in erythemal UV is expected as a consequence of dilution.

[37] As a final step in our analysis, the change in total column ozone was calculated using the TOMS data. The years 1979 and 1980 were taken as representatives of the preozone hole period, and the total change was derived with respect to the mean for these 2 years. In 1998, 1999 and 2000 , on average, the calculated ozone depletion in midlatitudes represented $83 \%, 87 \%$ and $95 \%$ of the total change in ozone, respectively. Although this simple comparison of ozone levels with the preozone hole period cannot be used to draw conclusions about ozone trends in southern midlatitudes, it should be noted that the results imply too high a contribution of dilution, as expected since the photochemical recovery along the trajectories was ignored.

\section{Discussion}

[38] The results presented here capture only one aspect of the influence of ozone depletion in the Antarctic ozone hole: how much more ozone there would have been in southern midlatitudes, had ozone inside the vortex not been depleted. In addressing this issue, a number of assumptions and approximations were made.

[39] First, even though the ozone deficit in the Antarctic vortex is expected to alter the stratospheric circulation in the SH [Prather et al., 1990; Mahlman et al., 1994], the observed winds were used in our study. Hence that aspect of the influence of the Antarctic ozone hole was neglected.

[40] Second, chemistry along parcel trajectories was not included, resulting in exclusion of additional ozone depletion and photochemical recovery. The study of Prather and Jaffe [1990] showed that in severely ozone-depleted air, additional ozone loss following transport into midlatitudes is not significant. Considering the severity of ozone depletion inside the Antarctic vortex air [e.g., Godin et al., 2001;
Hoppel et al., 2003], as well as the strong isolation of the Antarctic vortex prior to breakdown [e.g., Bowman, 1993; Pierce and Fairlie, 1993; Chen et al., 1994; Waugh, 1997], it was assumed that any additional ozone depletion can be neglected. On the other hand, the omission of the photochemical recovery can lead to an overestimate of the dilution effect. Knudsen and Groo $\beta$ [2000] showed that $\sim 18 \%$ of ozone-depleted air in northern midlatitudes photochemically recovers after about seven weeks. This result is somewhat higher than the result for southern midlatitudes of Prather et al. [1990], indicating a recovery of $\sim 14 \%$ during October and November, and of $\sim 20 \%$ from October to mid-January. Therefore reducing the December-January values, listed in Table 3, by $\sim 20 \%$ provides an indication of the dilution effect including photochemical recovery.

[41] Third, mixing between parcels was not explicitly represented in RDF calculations. The assumption that the mixing ratio of depleted ozone in a spatial box assigned to a vortex parcel is always the same, implies that the box was isolated from the surrounding air. However, mixing was implicitly included in the method by averaging depletion in the whole midlatitude region. The calculated mean value is insensitive to the amount of actual mixing that has occurred so long as the air remains in midlatitudes. The errors arise only when already diluted vortex air enters or leaves the analyzed region. As transport across the boundaries of subregions is larger, the results for subregions are more sensitive to mixing than the results for midlatitudes.

[42] Finally, the results presented here are limited by the fact that the calculations were performed for the $375-725 \mathrm{~K}$ layer, and for the time period between 15 October and 15 January of the following year. In southern midlatitudes, three regions were excluded from the domain: the region above $725 \mathrm{~K}$, the lowermost stratosphere (between $375 \mathrm{~K}$ and the tropopause), and the troposphere. As mentioned in section 2.4, on average, vortex air was descending, hence the exclusion of the stratosphere above $725 \mathrm{~K}$ should not influence the results. From the results presented in Prather et al. [1990], it can be inferred that ozone reduction around the tropopause $(\sim 10 \mathrm{~km})$ is $\sim 6 \%$, and in the troposphere $\sim 10 \%$ [also Brasseur et al., 1997]. A rough estimate of the combined depletion in these two regions is $\sim 0.8 \%$ of total column ozone (taking column ozone in the troposphere and around the tropopause as $\sim 5 \%$ of total column ozone each [McKenzie et al., 2003]). This implies that without dilution of the Antarctic ozone hole, there would have been $\sim 6-7 \%$ more ozone in southern midlatitudes.

[43] Another limiting factor in our results is the length of the analysis period. Since the persistence of ozone reduction in midlatitudes was analyzed up to 15 January, the results give only an immediate causal relationship between ozone depletion in the vortex and dilution in midlatitudes. Model studies of Prather et al. [1990], Mahlman et al. [1994], Eckman et al. [1996], and Chipperfield [1999] showed that ozone levels, both in the polar region and in midlatitudes, do not fully recover from depletion within a year. On the other hand, Bodeker et al. [2002] showed that in the polar region there was no negative trend in ozone for the month of May over 1981-2000, and concluded that there was no cumulative loss. Furthermore, the study of Fioletov and Shepherd [2003] suggested that there was no cumulative effect of ozone depletion even in midlatitudes $\left(35^{\circ} \mathrm{S}-60^{\circ} \mathrm{S}\right)$. 
With the results of Bodeker et al. [2002] and Fioletov and Shepherd [2003] it can be argued that except for previously discussed limitations, our method fully captures the dilution effect.

\section{Conclusions}

[44] The reduction in southern midlatitude ozone caused by the presence of the Antarctic vortex air parcels has been quantified for spring and early summer of 1998, 1999 and 2000. The results show that the mean ozone reduction was 16 DU, 18 DU and 19 DU in those years, respectively, corresponding, on average, to $5-6 \%$ of total column ozone.

[45] Ozone reduction in four longitudinal and three latitudinal subregions of southern midlatitudes has also been examined. The results indicate that the time-averaged impact was most pronounced in the regions encompassing South America and Africa, where, on average, there would have been $\sim 7 \%$ more ozone had there been no ozone depletion inside the Antarctic vortex during the preceding spring. The results also show that after vortex breakdown, in late December and early January, the reduction in ozone is effectively the same in all of the longitudinal regions. In the $60^{\circ}-50^{\circ} \mathrm{S}$ region, the time-averaged dilution impact was notably greater than in the $50^{\circ}-40^{\circ} \mathrm{S}$ and $40^{\circ}-30^{\circ} \mathrm{S}$ regions. However, in summer, the differences in ozone reduction between the latitudinal regions decreased.

[46] The reduction in ozone caused by the presence of vortex edge region parcels was significant, on average contributing at least $40 \%$ to the total reduction. The contribution of ozone depletion from the vortex edge region changed from month to month, ranging from more than $60 \%$ during October to $30-40 \%$ during January.

[47] Two caveats should be noted. First, the exclusion of ozone recovery from the calculations presented here leads to an overestimate of the dilution effect. Differences between the results of our study and similar analyses suggest that this effect should be included in future work. Second, our results do not capture the full impact of dilution as the lowermost stratosphere and troposphere have not been included in the calculations. The significance of the results nevertheless lies in the fact that the analyzed part of the stratosphere coincides with the region where ozone is most abundant. Furthermore, for the first time in the Southern Hemisphere, the immediate causal relationship between springtime ozone depletion in the Antarctic vortex and the ensuing ozone reduction in southern midlatitudes has been quantified.

[48] Acknowledgments. We are grateful for the provision of the Met Office stratospheric assimilation data (via BADC) and the TOMS data (via NASA/GSFC). We also thank Richard McKenzie for his helpful suggestions. This work was in part funded by a NIWA doctoral scholarship held at the University of Canterbury and by the University of Canterbury Research Assistant support.

\section{References}

Ajtić, J. (2003), Dilution of the Antarctic ozone hole into southern midlatitudes, Ph.D. thesis, Univ. of Canterbury, Christchurch, New Zealand

Ajtić, J., B. J. Connor, C. E. Randall, B. N. Lawrence, G. E. Bodeker, J. E. Rosenfield, and D. N. Heuff (2003), Antarctic air over New Zealand following vortex breakdown in 1998, Ann. Geophys., 21, 2175-2183.

Atkinson, R. J., and R. A. Plumb (1997), Three-dimensional ozone transport during the ozone hole breakup in December 1987, J. Geophys. Res., $102,1451-1466$.
Bodeker, G. E., H. Struthers, and B. J. Connor (2002), Dynamical containment of Antarctic ozone depletion, Geophys. Res. Lett., 29(7), 1098, doi:10.1029/2001GL014206.

Bowman, K. P. (1993), Large-scale isentropic mixing properties of the Antarctic polar vortex from analyzed winds, J. Geophys. Res., 98, 23,013-23,027.

Brasseur, G., and S. Solomon (1986), Aeronomy of the Middle Atmosphere, 2nd ed., D. Reidel, Norwell, Mass.

Brasseur, G. P., X. X. Tie, P. J. Rasch, and F. Lefèvre (1997), A threedimensional simulation of the Antarctic ozone hole: Impact of anthropogenic chlorine on the lower stratosphere and upper troposphere, J. Geophys. Res., 102, 8909-8930.

Bregman, A., M. van den Broek, K. S. Carslaw, R. Müller, T. Peter, M. P. Scheele, and J. Lelieveld (1997), Ozone depletion in the late winter lower Arctic stratosphere: Observations and model results, J. Geophys. Res., $102,10,815-10,828$

Brinksma, E. J., J. Ajtić, J. B. Bergwerff, G. E. Bodeker, I. S. Boyd, J. F. de Haan, W. Hogervorst, J. W. Hovenier, and D. P. J. Swart (2002), Five years of observations of ozone profiles over Lauder, New Zealand, J. Geophys. Res., 107(D14), 4216, doi:10.1029/2001JD000737.

Chen, P., J. R. Holton, A. O'Neill, and R. Swinbank (1994), Quasihorizontal transport and mixing in the Antarctic stratosphere, J. Geophys. Res., 99, 16,851-16,866.

Chipperfield, M. P. (1999), Multiannual simulations with a threedimensional chemical transport model, J. Geophys. Res., 104, $1781-1805$.

Chipperfield, M. P. (2003), A three-dimensional model study of long-term mid-high latitude lower stratosphere ozone changes, Atmos. Chem. Phys., 3, $1253-1265$.

Eckman, R. S., W. L. Grose, R. E. Turner, and W. T. Blackshear (1996), Polar ozone depletion: A three-dimensional chemical modeling study of its long-term global impact, J. Geophys. Res., 101, 22,977-22,989.

Fioletov, V. E., and T. G. Shepherd (2003), Seasonal persistence of midlatitude total ozone anomalies, Geophys. Res. Lett., 30(7), 1417, doi:10.1029/2002GL016739.

Godin, S., V. Bergeret, S. Bekki, C. David, and G. Mégie (2001), Study of the interannual ozone loss and the permeability of the Antarctic polar vortex from aerosol and ozone lidar measurements in Dumont d'Urville $\left(66.4^{\circ} \mathrm{S}, 140^{\circ} \mathrm{E}\right), \mathrm{J}$. Geophys. Res., 106, 1311-1330.

Hofmann, D. J., and S. Solomon (1989), Ozone destruction through heterogeneous chemistry following the eruption of El Chichón, J. Geophys. Res., 94, 5029-5041.

Holton, J. R., P. H. Haynes, M. E. McIntyre, A. R. Douglass, R. B. Rood, and L. Pfister (1995), Stratosphere-troposphere exchange, Rev. Geophys., 33, 403-439.

Hoppel, K., R. Bevilacqua, G. Nedoluha, C. Deniel, F. Lefèvre, J. Lumpe, M. Fromm, C. Randall, J. Rosenfield, and M. Rex (2002), POAM III observations of arctic ozone loss for the 1999/2000 winter, J. Geophys. Res., 107(D20), 8262, doi:10.1029/2001JD000476.

Hoppel, K., R. Bevilacqua, D. Allen, G. Nedoluha, and C. Randall (2003), POAM III observations of the anomalous 2002 Antarctic ozone hole, Geophys. Res. Lett., 30(7), 1394, doi:10.1029/2003GL016899.

Kirchhoff, V. W. J. H., Y. Sahai, C. A. R. S. Casiccia, F. B. Zamorano, and V. V. Valderrama (1997), Observations of the 1995 ozone hole over Punta Arenas, Chile, J. Geophys. Res., 102, 16,109-16,120.

Knight, J. R., J. Austin, R. G. Grainger, and A. Lambert (1998), A threedimensional model simulation of the impact of Mt. Pinatubo aerosol on the Antarctic ozone hole, Q. J. R. Meteorol. Soc., 124, 1527-1558.

Knudsen, B. M., and J.-U. Grooß (2000), Northern midlatitude stratospheric ozone dilution in spring modeled with simulated mixing, J. Geophys. Res., 105, 6885-6890.

Knudsen, B. M., W. A. Lahoz, A. O'Neill, and J.-J. Morcrette (1998), Evidence for a substantial role for dilution in northern mid-latitude ozone depletion, Geophys. Res. Lett., 25, 4501-4504.

Lee, A. M., H. K. Roscoe, A. E. Jones, P. H. Haynes, E. F. Shuckburgh, M. W. Morrey, and H. C. Pumphrey (2001), The impact of the mixing properties within the Antarctic stratospheric vortex on ozone loss in spring, J. Geophys. Res., 106, 3203-3211

Li, S., E. C. Cordero, and D. J. Karoly (2002), Transport out of the Antarctic polar vortex from a three-dimensional transport model, J. Geophys. Res., 107(D11), 4132, doi:10.1029/2001JD000508.

Lucke, R. L., et al. (1999), The Polar Ozone and Aerosol Measurement (POAM) III instrument and early validation results, J. Geophys. Res., 104, 18,785-18,799.

Mahlman, J. D., J. P. Pinto, and L. J. Umscheid (1994), Transport, radiative, and dynamical effects of the Antarctic ozone hole: A GFDL "SKYHI" model experiment, J. Atmos. Sci., 51, 489-508.

Manney, G. L., R. W. Zurek, A. O’Neill, and R. Swinbank (1994), On the motion of air through the stratospheric polar vortex, J. Atmos. Sci., 51, $2973-2994$. 
Manney, G. L., J. L. Sabutis, S. Pawson, M. L. Santee, B. Naujokat, R. Swinbank, M. E. Gelman, and W. Ebisuzaki (2003), Lower stratospheric temperature differences between meteorological analyses in two cold Arctic winters and their impact on polar processing studies, J. Geophys. Res., 108(D5), 8328, doi:10.1029/2001JD001149.

McKenzie, R., B. Connor, and G. Bodeker (1999), Increased summertime UV radiation in New Zealand in response to ozone loss, Science, 285, $1709-1711$

McKenzie, R., D. Smale, G. Bodeker, and H. Claude (2003), Ozone profile differences between Europe and New Zealand: Effects on surface UV irradiance and its estimation from satellite sensors, J. Geophys. Res., 108(D6), 4179, doi:10.1029/2002JD002770.

McPeters, R. D., et al. (1998), Earth Probe Total Ozone Mapping Spectrometer (TOMS) data products user's guide, NASA Tech. Publ., 1998 206895.

Morris, G. A., et al. (1995), Trajectory mapping and applications to data from the Upper Atmosphere Research Satellite, J. Geophys. Res., 100, $16,491-16,505$

Nash, E. R., P. A. Newman, J. E. Rosenfield, and M. R. Schoeberl (1996), An objective determination of the polar vortex using Ertel's potential vorticity, J. Geophys. Res., 101, 9471-9478.

Norton, W. A., and M. P. Chipperfield (1995), Quantification of the transport of chemically activated air from the Northern Hemisphere polar vortex, J. Geophys. Res., 100, 25,817-25,840.

Öllers, M. C., P. F. J. van Velthoven, H. M. Kelder, and L. P. J. Kamp (2002), A study of the leakage of the Antarctic polar vortex in late austral winter and spring using isentropic and 3-D trajectories, J. Geophys. Res., 107(D17), 4328, doi:10.1029/2001JD001363.

Pérez, A., E. Crino, I. A. de Cárcer, and F. Jaque (2000), Low-ozone events and three-dimensional transport at midlatitudes of South America during springs of 1996 and 1997, J. Geophys. Res., 105, 4553-4561.

Pierce, R. B., and T. D. A. Fairlie (1993), Chaotic advection in the stratosphere: Implications for the dispersal of chemically perturbed air from the polar vortex, J. Geophys. Res., 98, 18,589-18,595.

Prather, M., and A. H. Jaffe (1990), Global impact of the Antarctic ozone hole: Chemical propagation, J. Geophys. Res., 95, 3473-3492.

Prather, M., M. M. Garcia, R. Suozzo, and D. Rind (1990), Global impact of the Antarctic ozone hole: Dynamical dilution with a three-dimensional chemical transport model, J. Geophys. Res., 95, 3449-3471.

Rosenfield, J. E., and M. R. Schoeberl (2001), On the origin of polar vortex air, J. Geophys. Res., 106, 33,485-33,497.

Rosenfield, J. E., P. A. Newman, and M. R. Schoeberl (1994), Computations of diabatic descent in the stratospheric polar vortex, J. Geophys. Res., 99, 16,677-16,689.
Schoeberl, M. R., and L. C. Sparling (1995), Trajectory modelling, in Diagnostic Tools in Atmospheric Science, edited by G. Fiocco and G. Visconti, pp. 289-305, IOS Press, Amsterdam.

Stohl, A. (1998), Computation, accuracy and applications of trajectoriesA review and bibliography, Atmos. Environ., 32, 947-966.

Sutton, R. T., H. Maclean, R. Swinbank, A. O'Neill, and F. W. Taylor (1994), High-resolution stratospheric tracer fields estimated from satellite observations using Lagrangian trajectory calculations, J. Atmos. Sci., 51, $2995-3005$

Swinbank, R., and A. O'Neill (1994), A stratosphere-troposphere data assimilation system, Mon. Weather Rev., 122, 686-702.

Tao, X., and A. F. Tuck (1994), On the distribution of cold air near the vortex edge in the lower stratosphere, J. Geophys. Res., 99, 3431-3450.

Tuck, A. F., and M. H. Proffitt (1997), Comment on "On the magnitude of transport out of the Antarctic polar vortex" by Wiel M. F. Wauben et al., J. Geophys. Res., 102, 28,215-28,218.

Waugh, D. W. (1997), Elliptical diagnostics of stratospheric polar vortices, Q. J. R. Meteorol. Soc., 123, 1725-1748.

Waugh, D. W., and P.-P. Rong (2002), Interannual variability in the decay of lower stratospheric Arctic vortices, J. Meteorol. Soc. Jpn., 80, 997-1012. Waugh, D. W., et al. (1997), Mixing of polar vortex air into middle latitudes as revealed by tracer-tracer scatterplots, J. Geophys. Res., 102, 13,11913,134 .

World Meteorological Organization (WMO) (2003), Scientific assessment of ozone depletion: 2002, Rep. 47, Global Ozone Res. and Monitor. Proj., Geneva, Switzerland.

J. Ajtić, G. E. Bodeker, and B. J. Connor, National Institute of Water and Atmospheric Research Lauder, Private Bag 50061, Omakau 9182, New Zealand.(j.ajtic@niwa.co.nz; g.bodeker@niwa.cri.nz; b.connor_@niwa. co.nz)

D. N. Heuff, Department of Physics and Astronomy, University of Canterbury, Private Bag 4800, Christchurch 8020, New Zealand. (d.heuff@canterbury.ac.nz)

K. W. Hoppel, Remote Sensing Physics Branch, Code 7227, Naval Research Lab, Washington, DC 20375-5320, USA. (karl.hoppel@nrl. navy.mil)

B. N. Lawrence, British Atmospheric Data Centre, Rutherford Appleton Laboratory, Chilton, Didcot, OX11 0QX, UK. (b.n.lawrence@rl.ac.uk)

J. E. Rosenfield, Goddard Earth Sciences and Technology Center, NASA/ Goddard Space Flight Center, Code 916, Greenbelt, MD 20771, USA. (rose@euterpe.gsfc.nasa.gov) 